\title{
Functional and Morphological Changes in the Hypothalamus-Pituitary Posterior Lobe System after Hypophysectomy in the Dog
}

\author{
Takahiro TAODA ${ }^{1)}$, Yasushi HARA ${ }^{1)}$, Hiroyuki MASUDA ${ }^{1)}$, Yoshinori NEZU1), Naoko SANNO ${ }^{2)}$, Akira TERAMOTO ${ }^{2)}$ \\ Susumu TAKEKOSHI ${ }^{3)}$, Robert Y. OSAMURA ${ }^{3)}$ and Masahiro TAGAWA ${ }^{1)}$ \\ ${ }^{1)}$ Division of Veterinary Surgery, School of Veterinary Medicine, Nippon Veterinary and Animal Science University, 1-7-1 Kyonan-cho, \\ Musashino-shi, Tokyo 180-8602, ${ }^{2)}$ Department of Neurosurgery, Nippon Medical School, 1-1-5 Sendagi, Bunkyo-ku, Tokyo 113-8603 \\ and ${ }^{3)}$ Department of Pathology, Tokai University School of Medicine, Boseidai, Isehara-shi, Kanagawa 259-1193, Japan
}

(Received 12 April 2005/Accepted 30 August 2005)

\begin{abstract}
Acute diabetes insipidus-like symptoms have been reported as a complication after hypophysectomy in dogs. These symptoms are believed to be the consequence of deficiency of arginine vasopressin (AVP) secretion. The symptoms spontaneously resolve within 2 weeks, but the mechanism is unclear. In the present study, AVP secretion related to increases in $\mathrm{Na}^{+}$concentration and serum osmotic pressure was measured, and immunohistochemical analysis in the paraventricular and supraoptic nuclei was perfomed after hypophysectomy in normal dog. In the hypertonic saline test, the plasma AVP concentration slightly increased in hypophysectomized dogs, although the increase was markedly smaller than that in normal dogs. An immunohistochemical study of the hypothalamus nucleus revealed that, AVP-positive cells tended to decrease after hypophysectomy. It suggests that excision of the posterior lobe by surgery injured the axon of magnocellular neuron in the hypothalamus. A decrease in the function and the number of AVP-producing and -secreting magnocellular neurons after hypophysectomy, suggests that the clinical improvement of postoperative diabetes insipidus-like symptoms may not be related to the recovery of AVP secretion.

KEY WORDS: arginine vasopressin, canine, hypophysectomy, hypothalamus, pituitary.
\end{abstract}

J. Vet. Med. Sci. 68(1): 1-7, 2006

In the field of neurosurgery, disorders of the hypothalamic/posterior pituitary occur in humans after surgery of the hypothalamus and its proximal region. Abnormal water and electrolyte metabolism are typical postoperative complications. Unlike chronic disease, this postoperative metabolic abnormality develops acutely within a few hr after surgery in many cases; and these disorders with marked polydipsia and polyuria often resolve within a few days.

In the field of veterinary neurosurgery, hypophysectomy is recognized as a useful surgical treatment for canine pituitary tumors such as anterior and intermediate pituitary adenoma that cause Cushing's syndrome. However, in dogs, hypophysectomy also induces acute diabetes insipidus-like symptoms as a post-operative complication, which is believed to be the result of decreased arginine vasopressin (AVP) secretion. This sequence of events is a serious problem in humans as well [14, 16, 19, 21, 22, 24].

In our previous study, severe diabetes insipidus-like symptoms developed within a few hr after hypophysectomy in dogs, but the symptoms disappeared within about 2 weeks [10]. In the present study, we investigated the disappearance of postoperative diabetes insipidus-like symptoms. AVP secretion related to increases in $\mathrm{Na}^{+}$concentration and serum osmotic pressure was measured, and immunohistochemical analysis in the paraventricular and supraoptic nuclei were performed after hypophysectomy in normal dogs.

\section{MATERIALS AND METHODS}

Animals: Clinically and neurologically normal beagles (7 males and 7 females), aged 1-9 years (mean: 3.0 years old), weighing $8.0-14.0 \mathrm{~kg}$ (mean: $11.4 \mathrm{~kg}$ ), with normal values in a complete blood count, blood chemistry, blood gas analysis, and serum electrolyte test, were randomly divided into a control group ( $\mathrm{n}=5 ; 3$ males and 2 females), a 1-month group $(\mathrm{n}=4 ; 4$ males $)$, and a 3 -month group $(\mathrm{n}=5 ; 5$ females).

Experimental design: The animals in the control group were observed for 1 month without experimental hypophysectomy and treatment. Daily water consumption (DWC) and daily urine volume (DUV) were measured after that time. Specific gravity of urine (USG) of the animals was also measured. A hypertonic saline test was performed subsequently.

In the 1-month and 3-month groups, hypophysectomy was performed. After follow-up for 1 and 3 months respectively, DWC, DUV, and USG were measured in the same manner as in the control group. After the hypertonic saline solution load test, animals were sacrificed by excess administration of sodium pentobarbital, and the hypothalamic tissue was excised for histological examination.

The experimental protocol was approved by the Committee on Bioethics of Nippon Veterinary and Animal Science University.

Hypophysectomy: In the 1-month and 3-month groups, hypophysectomy was conducted according to the technique reported by Meij, B. P. et al. [16, 19, 21, 22]. The hypophyseal stalk connecting to the third ventricle was completely resected in the present study. The dogs received Lactated Ringer's solution $(10 \mathrm{mg} / \mathrm{kg} / \mathrm{hr}$, intravenous drip) during surgery. For prevention of infection, chloramphenicol 
sodium succinate $(25 \mathrm{mg} / \mathrm{kg}$, intravascular injection (iv) ) (Sankyo Lifetech Co., Ltd., Tokyo, Japan) and enrofloxacine $(5 \mathrm{mg} / \mathrm{kg}$, intramuscular injection (im) ) (Bayer yakuhin, Ltd., Osaka, Japan) were administered immediately after induction of anesthesia, and tranexamic acid $(250 \mathrm{mg} /$ head, iv) (Daiichi Pharmaceutical Co., Ltd., Tokyo, Japan) and carbazochrome sodium sulfonate $(10 \mathrm{mg}$, im) (Tanabe Seiyaku Co., Ltd., Osaka, Japan) were administered as systemic hemostatics. The animals were given drinking water from the day of surgery, and antibiotics, chloramphenicol sodium succinate $(25 \mathrm{mg} / \mathrm{kg}$, iv, bis in di'e (BID)) and enfroxacine $(5 \mathrm{mg} / \mathrm{kg}, \mathrm{im}, \mathrm{BID})$, were administered for 2 weeks.

Evaluation of clinical findings and physical parameters: As general clinical findings after hypophysectomy in the 1month and 3-month groups, neurological abnormalities (consciousness level, manifestation of abnormal behavior, hyperesthesia, and postural reaction) were evaluated daily during the follow-up period. Respiratory symptoms (hyperventilation, cough, serous or purulent nasal flow) were also evaluated daily. DWC, DUV, and USG were measured in the control, 1-month, and 3-month groups. The evaluations and measurements were performed at noon each day.

Hypertonic saline test: After the measurements of DWC, DUV and USG, the hypertonic saline test was performed according to the method reported by Rijnberk A. et al., with minor a modification [27]. The test was carried out before sacrifice in the control group. In the 1-month, and 3-month groups, tests were carried out at 1 month after surgery, and 3 months after surgery, respectively. In the hypertonic saline test, plasma AVP concentration, plasma osmolality, and serum $\mathrm{Na}^{+}$concentration were measured [2,27]. Using a microinstillator (Terumo Corporation, Tokyo, Japan), a $10 \% \mathrm{NaCl}$ solution $(0.06 \mathrm{ml} / \mathrm{kg} / \mathrm{min}$, iv) (Otsuka Pharmaceutical Co., Ltd., Tokyo, Japan) was continuously administered for $2 \mathrm{hr}$. Blood was collected from the cephalic vein of the foreleg, before administration, and 60 and $120 \mathrm{~min}$ after administration. The plasma AVP concentration, serum $\mathrm{Na}^{+}$ concentration, and plasma osmolality were measured at each time point. Blood samples treated with ethylene diamine tetra acetic acid were used for the measurement of the plasma AVP concentration and plasma osmolality. And blood samples collected in heparin-treated syringes were used for measurement of the serum $\mathrm{Na}^{+}$concentration. Plasma and serum were separated by cold centrifuge $\left(4^{\circ} \mathrm{C}\right.$, $1,470 \times \mathrm{g}, 15 \mathrm{~min})$. The plasma AVP concentration was measured by the RIA two-antibodies method (AVP RIA MITSUBISHI, Mitsubishi Kagaku Iatron Inc., Tokyo, Japan), and plasma osmolality was measured by the cryoscopic method. Serum $\mathrm{Na}^{+}$concentration was measured by the use of a blood electrolyte analyzer (AVL Na-K-Cl analyzer, AVL Scientific Corporation, Roswell, GA).

Immunohistochemical staining: After sacrifice, hypothalamic tissue was harvested, then excised as a $15 \times 15 \times 15$ $\mathrm{mm}^{3}$ cube so as to contain the median eminence at the center of the cube base. The cube was then further cut into 4 blocks in the frontal plane. The blocks were then fixed in
$4 \%$ paraformaldehyde at $4^{\circ} \mathrm{C}$ for $24 \mathrm{hr}$, embedded in paraffin, and thin-sectioned. The tissue sections were stained immunohistochemically using the peroxidase-labeled antibody method $[25,29]$. Anti-AVP antibody (antihuman IgG, rabbit, polyclonal)(Sigma Aldrich Co., Missouri, U.S.A.) was used. The tissue sections were deparaffinized with xylene, and rinsed with $100 \%$ ethanol. After endogenous peroxidase was blocked with $0.3 \% \mathrm{H}_{2} \mathrm{O}_{2}$ at room temperature for $30 \mathrm{~min}$, the sections were rinsed with $0.01 \mathrm{M}$ phosphate buffered saline (PBS). Anti-AVP antibody was placed on the tissue sections, and reacted at $4^{\circ} \mathrm{C}$ overnight. After the sections were rinsed with PBS, anti-rabbit antibody (anti-rabbit IgG, donkey, F(ab')2)(Amersham Bioscience Corp., NJ, U.S.A.) was added to the sections as the secondary antibody, and reacted at room temperature for 30 min. The sections were then rinsed with PBS, and the antigen-antibody complexes were rendered visible by reaction with $50 \mathrm{mM}$ Tris- $\mathrm{HCl}$ buffer (pH7.6) containing $0.05 \%$ 3,3'-diamino benzidine-4HCl (DAB). The sections were also stained with methyl green for 30 min for nuclear staining.

In the hypothalamic tissue, AVP-immunopositive cells in each of the paraventricular and supraoptic nuclei were counted in each section, and the section of highest counts was adopted as the positive cell count of the animal.

Statistical analysis: For intergroup comparison of DWC, DUV, and USG, the student's $t$-test was used. For intergroup comparison of the plasma AVP concentration at each point in the hypertonic saline test, the student's $t$-test was also used. From the outcome in the hypertonic saline test, the correlation between $\mathrm{Na}^{+}$and AVP concentration, and the correlation between plasma osmolality and AVP concentration were investigated in each group. In these comparisons, $p<0.05$ was regarded as significant. In addition, similarity of regression lines obtained in each group was investigated by analysis of covariance, and $p<0.01$ was regarded as significant. The AVP-positive cell counts in the paraventricular and supraoptic nuclei in the hypothalamic tissue were compared among the groups by the student's $t$-test, and $\mathrm{p}<0.05$ was regarded as significant.

\section{RESULTS}

Clinical findings: All animals in the 1-month and 3month groups started drinking water after recovery of anesthesia, and started eating feed on the next day. No marked neurological abnormalities or respiratory symptoms were noted in any of the animals throughout the follow-up period, and their activity and appetite were maintained.

Changes in DWC, DUV, and USG: DWC and DUV were higher, and USG was lower in the 1-month and 3-month groups compared with those in the control group, but the differences were not significant (Table 1).

Changes in plasma AVP and serum $\mathrm{Na}^{+}$concentrations and plasma osmolality in hypertonic saline test: Plasma AVP concentrations before hypertonic saline infusion were $1.78 \pm 0.52$ (mean \pm standard deviation $(\mathrm{SD})) \mathrm{pg} / \mathrm{ml}$ in the 
Table 1. Daily water consumption (DWC), daily urine volume (DUV), and specific gravity of urine (USG) in each group

\begin{tabular}{lcll}
\hline & $\begin{array}{c}\text { DWC } \\
(\mathrm{m} / \mathrm{kg} / \text { day })\end{array}$ & $\begin{array}{c}\mathrm{DUV} \\
(\mathrm{m} / / \mathrm{kg} / \text { day })\end{array}$ & USG \\
\hline Control group & $75.40 \pm 46.64$ & $24.00 \pm 12.35$ & $1.035 \pm 0.017$ \\
1-month group & $41.75 \pm 13.25$ & $30.50 \pm 9.26$ & $1.026 \pm 0.018$ \\
3-month group & $53.00 \pm 22.19$ & $36.20 \pm 18.63$ & $1.030 \pm 0.013$ \\
\hline
\end{tabular}

Each value represents mean \pm standard deviation (SD), respectively. Each measurements in the 1-month and 3-month groups, were performed after follow-up for 1- and 3-month after hypophysectomy respectively. Intergroup comparison of DWC and DUV and USG, revealed no significant difference. However, DWC and DUV were higher and USG was lower in the 1-month and 3-month groups as compared to those in the control group.

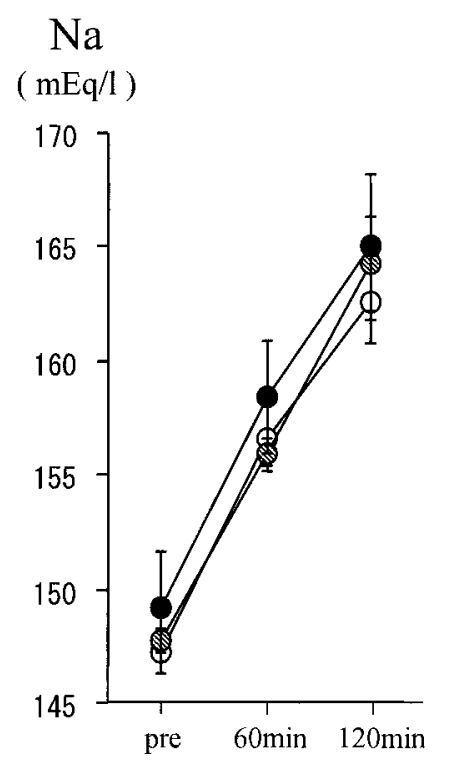

\section{Osmolality \\ $(\mathrm{mOsmol} / \mathrm{kg}$ )}

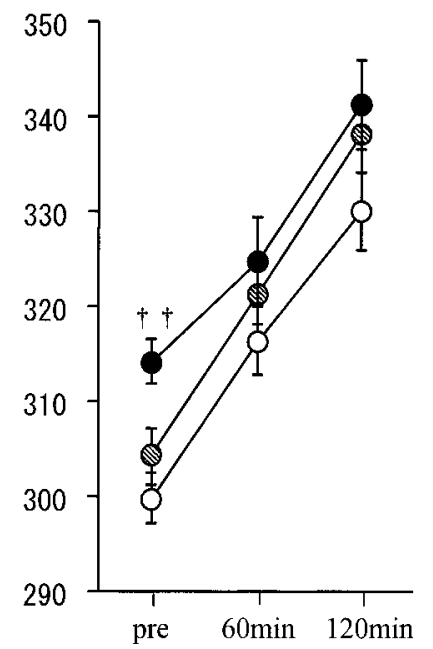

AVP

$(p \mathrm{~g} / \mathrm{ml})$

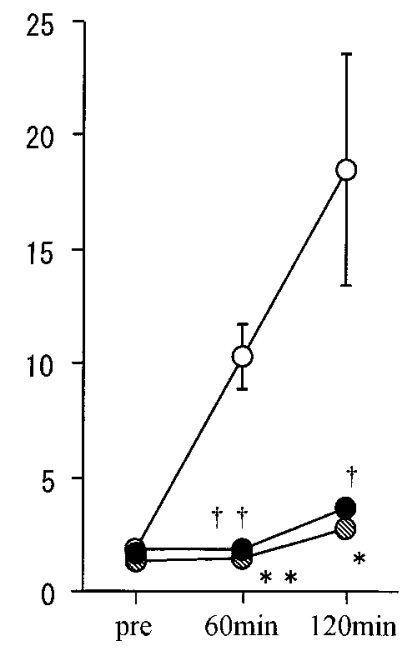

Fig. 1. Changes in plasma arginine vasopressin (AVP), serum $\mathrm{Na}^{+}$concentration and plasma osmolality in hypertonic saline test. In the 1-month and 3-month groups, the serum $\mathrm{Na}^{+}$concentration and plasma osmolality increased with hypertonic saline infusion as in the control group. However, plasma AVP concentration was significantly lower than in the control group at 60 and $120 \mathrm{~min}$, although it slightly increased with loading of hypertonic saline. Each symbol and bar represents mean and SD, respectively. - $\mathrm{O}-$ : control group, $-\mathrm{O}^{-}$: 1-month group, $-\mathrm{O}^{-}$: 3-month group. *, $* *$ : Significantly different from the control group at $p<0.05, p<0.01$, respectively. $\uparrow, \uparrow \dagger$ : Significantly different from the control group at $p<0.05, p<0.01$, respectively.

control group, $1.28 \pm 0.26 \mathrm{pg} / \mathrm{m} l$ in the 1-month group, and $1.74 \pm 0.67 \mathrm{pg} / \mathrm{ml}$ in the 3-month group. The differences between these values were not statistically significant. In the control group, plasma AVP concentration increased in response to elevation of the $\mathrm{Na}^{+}$concentration and plasma osmolality with hypertonic saline infusion. In the 1-month and 3-month groups, the $\mathrm{Na}^{+}$concentration and plasma osmolality increased with hypertonic saline infusion as in the control group, but the plasma AVP concentration was significantly lower than that in the control group at 60 and $120 \mathrm{~min}(p<0.0011, p<0.0288$ in 1-month group compared to the control, and $p<0.0005, p<0.0195$ in 3-month group compared to the control.) (Fig.1).

Correlation between serum $\mathrm{Na}^{+}$and plasma AVP con- centrations in hypertonic saline test: When correlation between the $\mathrm{Na}^{+}$and plasma AVP concentrations in each group in the hypertonic saline test was analyzed, the correlation coefficient, $r$, and the regression line were $r=0.707$ and $\mathrm{Y}=-134.236+0.929 \mathrm{X}$ in the control group, $r=0.683$ and $\mathrm{Y}=-9.745+0.074 \mathrm{X}$ in the 1-month group, and $r=0.442$ and $Y=-6.137+0.054 \mathrm{X}$ in the 3 -month group. No similarities of the regression lines were observed between the control group and each of the 1-month and 3-month groups $(p<0.01)$ (Fig. 2). No significant difference was noted on comparison of the regression lines between the 1-month and 3-month groups.

Correlation between plasma osmolality and plasma AVP concentration in hypertonic saline test: When correlation 

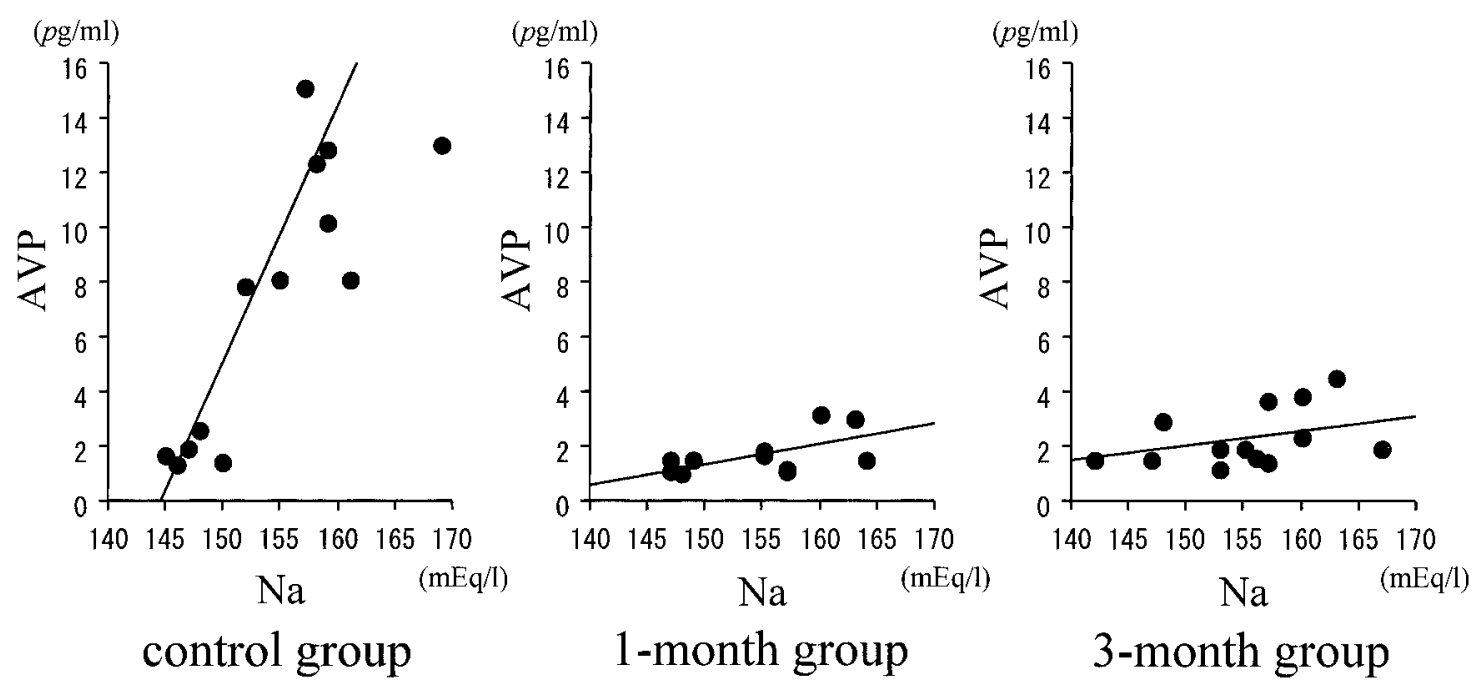

Fig. 2. Correlation between serum $\mathrm{Na}^{+}$and plasma AVP concentrations in hypertonic saline test in each group. The correlation coefficient $r$, and the regression line were $r=0.707$ and $\mathrm{Y}=-134.236+0.929 \mathrm{X}$ in the control group, $r=0.683$ and $\mathrm{Y}=-9.745+$ $0.074 \mathrm{X}$ in the 1-month group, and $r=0.442$ and $\mathrm{Y}=-6.137+0.054 \mathrm{X}$ in the 3 -month group. No similarities of the regression lines were observed between the control group and each of the 1-month and 3-month groups $(p<0.01)$.

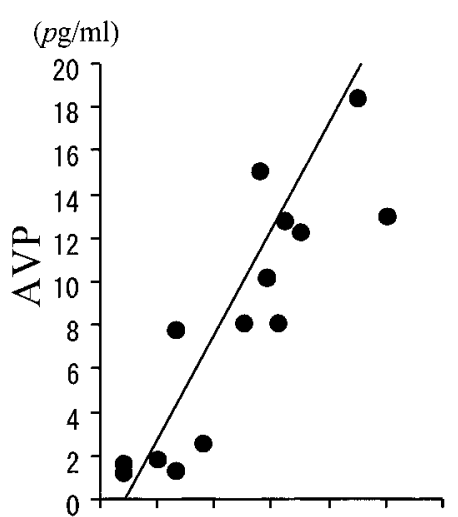

$290 \quad 300310320330340 \quad 350$

Osmolality $(\mathrm{mOsmol} / \mathrm{kg})$

control group

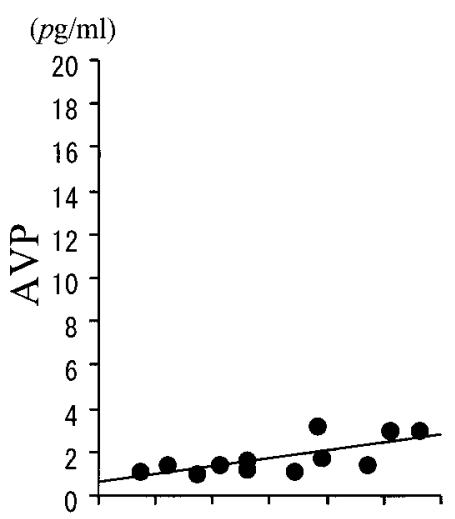

290300310320330340350

Osmolality ${ }^{(\mathrm{mOsmol} / \mathrm{kg})}$

1-month group

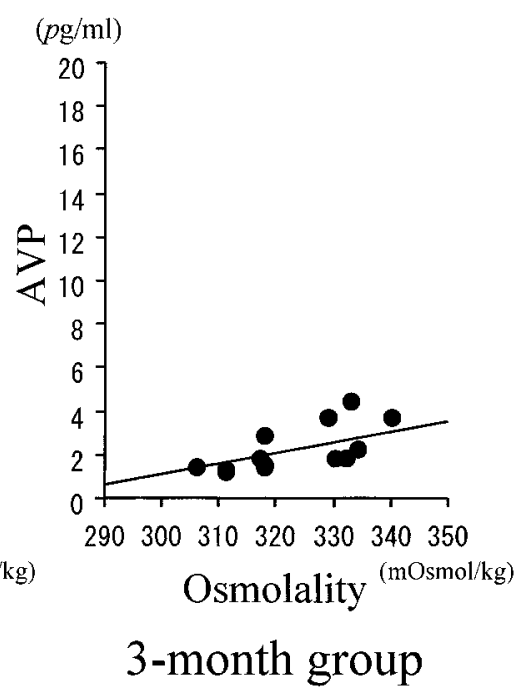

3-month group

Fig. 3. Correlation between plasma osmolality and plasma AVP concentration in hypertonic saline test. The correlation coefficient $r$, and the regression line were $r=0.758$ and $\mathrm{Y}=-143.794+0.488 \mathrm{X}$ in the control group, $r=0.703$ and $\mathrm{Y}=-9.812+$ $0.036 \mathrm{X}$ in the 1-month group, and $r=0.635$ and $\mathrm{Y}=-13.318+0.048 \mathrm{X}$ in the 3-month group. No similarities of the regression lines were observed between the control group and each of the 1-month and 3-month groups $(p<0.01)$.

between the plasma osmolality and plasma AVP concentration in each group in the hypertonic saline test were analyzed, the correlation coefficient $r$ and the regression line were $r=0.758$ and $\mathrm{Y}=-143.794+0.488 \mathrm{X}$ in the control group, $r=0.703$ and $\mathrm{Y}=-9.812+0.036 \mathrm{X}$ in the 1 -month group, and $r=0.635$ and $\mathrm{Y}=-13.318+0.048 \mathrm{X}$ in the 3 month group. No similarities of the regression lines were observed between the control group and each of the 1-month and 3-month groups $(p<0.01$, Fig. 3). Comparison of the regression lines between the 1-month and 3-month groups, revealed no significant difference.

AVP-positive cell counts: Immunohistochemistry using anti-AVP antibody was performed in the diencephalohypothalamic region, and AVP-positive cells were counted in each of the paraventricular and supraoptic nuclei (Fig. 4). The mean AVP-positive cell numbers in the paraventricular nucleus were $111.5,45.0$, and 43.7 cells/slice in the control, 1-month, and 3-month groups, respectively, showing that 

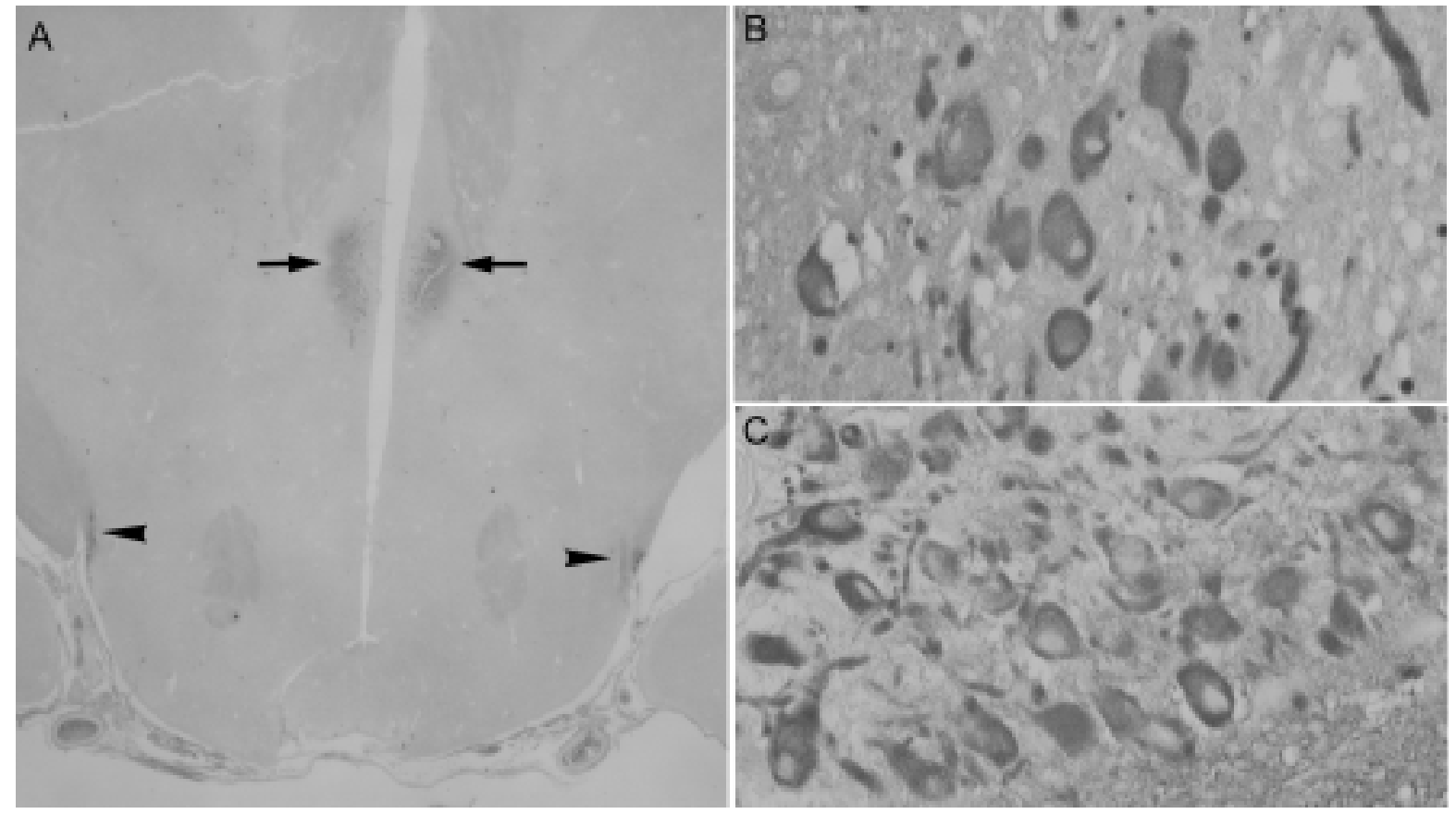

Fig. 4. Immunohistochemistry in the diencephalohypothalamic region (AVP-positive cell in paraventricular and supraoptic nuclei). A: Frontal plane of diencephalohypothalamic region: paraventricular nuclei (arrows) and supraoptic nuclei (arrowheads) $(\times 5)$. B: AVPpositive cell in paraventricular nuclei $(\times 200)$. C: AVP-positive cell in supraoptic nuclei $(\times 200)$.
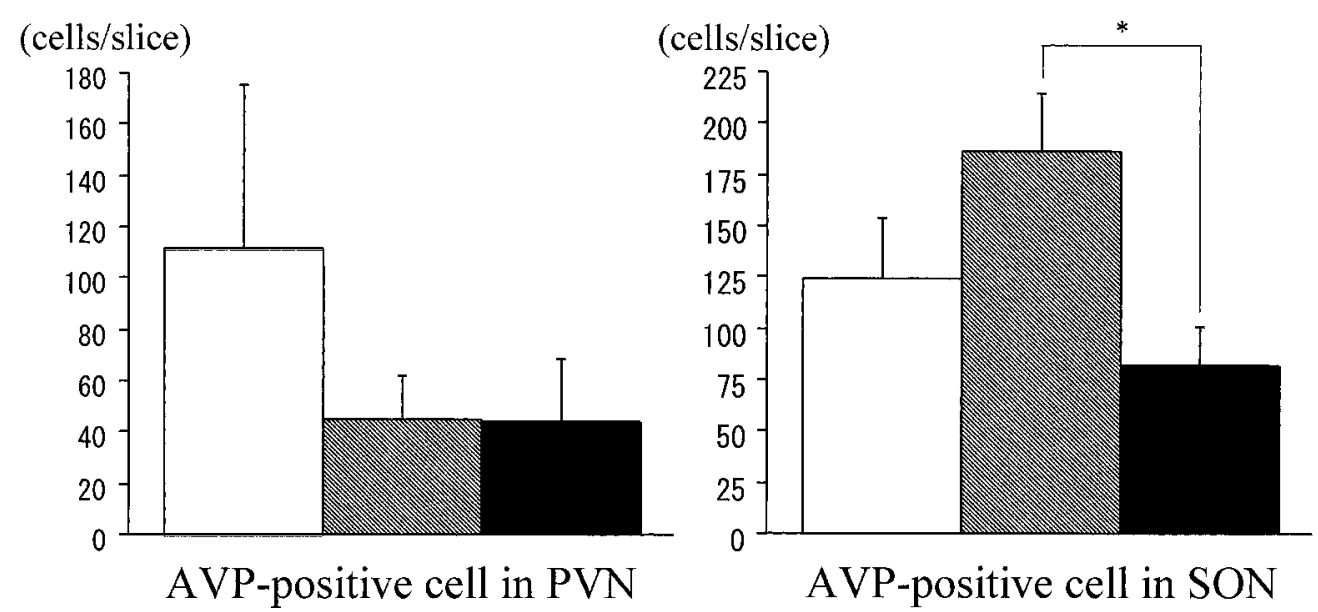

Fig. 5. AVP-positive cell counts in the paraventricular and supraoptic nuclei. AVP-positive cell counts were lower in the l-month and 3-month groups than in the control group in the paraventricular nucleus. In the supraoptic nucleus, the count tended to decrease from the 1-month to the 3-month group. In addition, the cell count was significantly lower in the 3 -month group than in the 1-month group in the supraoptic nucleus $(p<0.05)$. Each column and bar represents mean and SD, respectively. $\square$ : control group, $\square$ : 1-month group, $\square$ : 3-month group. * Significantly different from the control group at $p<0.05$.

the number was lower in the 1-month and 3-month groups than in the control group. In the supraoptic nucleus, the mean AVP-positive cell numbers were 123.8, 186.0, and 82.6 cells/slice in the control, 1-month, and 3-month groups, respectively, and the number tended to decrease from the 1month group to the 3-month group (Fig. 5). In addition, the cell count in the supraoptic nucleus was significantly lower in the 3-month group than in the 1-month group $(p<0.05)$. 


\section{DISCUSSION}

Hypophysectomy in dogs has a long history in the field of experimental medicine, but there have been only a few clinical reports in the field of neurosurgery of small animals after introduction of hypophysectomy as a therapy for pituitary dependent hyperadrenocorticism (PDH) in 1968 [17, 20, 22].

In 1998, Meij B. P., et al. reported clinical outcomes of transsphenoidal hypophysectomy in dogs with PDH [21]. Also in other previous reports, the major complications after hypophysectomy in dogs were acute diabetes insipidus-like symptoms accompanied by postoperative polydipsia and polyuria $[18,22,24]$. Diabetes insipidus accompanied by abnormalities of electrolyte metabolism, such as central hypernatremia or central hyponatremia after cerebral neurosurgery in dogs has also been reported [21,24].

Diabetes insipidus is pathologic for a decreased ability of the kidney to concentrate urine due to either decreased secretion of AVP from the posterior pituitary gland, or resistance of the renal collecting duct to the action of AVP. Postoperative diabetes insipidus presents within $24 \mathrm{hr}$ after surgery, and spontaneously resolves within a few days.

For these postoperative diabetes insipidus-like symptoms, various biological compensatory systems may act to resolve the symptoms, such as residual vasopressin secretion, a decrease in glomerular filtration with elevation of plasma osmolality, promotion of re-absorption of water and $\mathrm{Na}^{+}$in the proximal convoluted tubule, an increase in water intake induced by stimulation of the thirst center, potentiation of angiotensin-induced aldosterone secretion from the adrenal cortex due to promotion of the renin-angiotensin system, and promotion of thirst and water intake $[1,5,8,9]$.

In the present study, water consumption and urinary volume were the largest at 1 day after surgery (means: 380.0 $\mathrm{m} l / \mathrm{kg} /$ day and $336.0 \mathrm{~m} l / \mathrm{kg} /$ day, respectively). Values decreased thereafter, and returned to the normal range within 2 weeks in the hypophysectomized 3-month group. Specific gravity of urine was also lowest at 1 day after surgery (mean=1.004), and returned to the normal range within 2 weeks.

AVP is mainly secreted by large neurosecretory cells in the hypothalamic paraventricular and supraoptic nuclei. It descends along the nerve axon, and is stored in the posterior pituitary gland through the inner layer of the median eminence. Total resection of the pituitary gland results in loss of storage and secretion capability for AVP in the posterior pituitary in animals. However, when the pituitary stalk was sectioned low enough so as to not cause degenerative changes in the bodies of the neurons in the paraventricular and supraoptic nuclei, magnocellular neurons formed a pseudo-posterior lobe by neurohemoral connection, and secreted AVP by leakage $[7,12,19]$. In the hypertonic saline test, plasma AVP concentration slightly increased in the 1-month and 3-month groups, although the increase was markedly smaller than that in the control group. This finding suggested that vasopressin was directly secreted (leaked) from the stump of the axon of magnocellular neurons that lost the neurosecretory terminal in the hypothalamus, although the amount was small. In this study, the pituitary gland was resected with its stalk below the hypothalamus, and no pseudoposterior lobe was formed. Thus, during the follow-up period, AVP may have been secreted from the axon stump at a level that prevented clinical diabetes insipidus-like symptoms, but insufficient enough to respond to hypertonic saline infusion [19]. This insufficient secretion was unable to normalize plasma osmolality at three months after hypophysectomy.

Immunohistochemical study of the hypothalamic nucleus revealed that AVP-positive cells tended to decrease after hypophysectomy, suggesting that excision of the posterior lobe by surgery injured the axon reaching the posterior lobe of magnocellular neurons in the hypothalamus. This impairment of axon transport caused accumulation of various proteins in the cell body and loss of intracellular organelles, resulting in atrophy of neuron cell bodies called degenerative changes $[15,23]$. Based on the finding that function and number of AVP-producing and -secreting magnocellular neurons reductioned after hypophysectomy, the recovery of AVP secretion may not be related to clinical improvement of postoperative diabetes insipidus-like symptoms.

With regards to the mechanism of spontaneous resolution within about 2 weeks of the diabetes insipidus-like symptoms that developed early after hypophysectomy, several biological compensatory mechanisms should be considered. It has been reported that in patients with central diabetes insipidus, long-term deficiency of AVP increased expression of $\mathrm{V} 2$ receptors to the maximum, increasing sensitivity to AVP even at a low concentration. Furthermore, exogenous AVP administration to patients with central diabetes insipidus induced a greater degree of urine concentration in some patients than in healthy subjects $[3,26,30]$.

Hypophysectomy also induces adrenocortical hypofunction and adrenal atrophy due to lack of adrenocorticotropic hormone stimulation. Subsequently, adrenal atrophy contributes to glucocorticoid hyposecretion. Glucocorticoid hyposecretion decreases glomerular filtration, and increases AVP secretion and action on the collecting tubule. Thus, hypocortisolemia induces resolution of the diabetes insipidus-like symptoms.

In addition to the above hypotheses of biological compensatory mechanisms, excess expression of aquaporin-2 (AQP-2) water channel in the collecting tubule in a dehydration state is possible $[4,6,11,13,28]$. AQP-2 senses extracellular osmotic pressure in the renal collecting tubule cells. It is believed that AQP-2 is overexpressed during dehydration, and actively reabsorbs water. Thus AQP-2 may influence regression of diabetes insipidus symptoms. Further study is necessary to investigate changes in number of the AVP receptor and AQP-2 in the renal collecting duct. Furthermore, humoral or neural factors other than AVP may compensate body fluid balance.

This study suggests the resolution of insipidus-like symp- 
toms is not related to an upregulation or recovery of magnocellular neurons in hypothalamus, as the function and number of AVP-secreting magnocellular neurons decreased after hypophysectomy. Receptor alterations after hypophysectomy in tissues containing various pituitary hormone receptors, particularly the adrenal cortex, renal glomeruli, uriniferous tubules, and collecting tubules should be investigated, as well as changes in the hypothalamus around the pituitary.

\section{REFERENCES}

1. Biewenga, W. J., Van den Brom, W. E. and Mol, J. A. 1987. The use of arginine vasopressin measurements in the polyuric dog. Tijdschr. Diergeneeskd. 112 (Suppl.) 1: 117-120.

2. Biewenga, W. J., Van den Brom, W. E. and Mol, J. A. 1987. Vasopressin in polyuric syndromes in the dog. Front. Horm. Res. 17: 139-148.

3. Boscaro, M., Mani, E., Pistorello, M. and Rampazzo, A. 1990. Treatment of diabetes insipidus. Minerva. Endocrinol. 15: 9599.

4. Deen, P. M., Verdijk, M. A., Knoers, N. V., Wieringa, B., Monnens, L. A., Van Os, C. H. and Van Oost, B. A. 1994. Requirement of human renal water channel aquaporin-2 for vasopressin-dependent concentration of urine. Science $\mathbf{2 6 4}$ : 92-95.

5. Epstein, A. N., Fitzsimons, J. T. and Simons, B. J. 1969. Drinking caused by the intracranial injection of angiotensin into the rat. J. Physiol. 200: 98-100.

6. Fernandez-Llama, P. 2000. Molecular physiology of the urinary concentration mechanism, role of renal aquaporins. Nefrologia 20: 486-494.

7. Fisher, C. and Ingram, W. R. 1936. The effect of interruption of the supraoptico-hypophyseal tracts on the antidiuretic pressor and oxytocic activity of the posterior lobe of the hypophysis. Endocrinology 20: 762-768.

8. Fitzsimons, J. T. 1969. The role of a renal thirst factor in drinking induced by extracellular stimuli. J. Physiol. 201: 349-368.

9. Fitzsimons, J. T. and Simons, B. J. 1969. The effect on drinking in the rat of intravenous infusion of angiotensin, given alone or in combination with other stimuli of thirst. J. Physiol. 203: 45-57.

10. Hara, Y., Masuda, H., Taoda, T., Hasegawa, D., Fujita, Y., Nezu, Y. and Tagawa, M. 2003. Prophylactic efficacy of desmopressin acetate for diabetes insipidus after hypophysectomy in the dog. J. Vet. Med. Sci. 65: 17-22.

11. Harris, H. W. Jr. and Zeidel, M. L. 1993. Water channels. Curr. Opin. Nephrol. Hypertens. 2: 699-707.

12. Heinbecker, P. and White, H. L. 1944. Hypothalamic-hypophysial system and its relation to water balance in the dog. Am. J. Physiol. 133: 582-593.

13. Knepper, M. A. 1997. Molecular physiology of urinary concentrating mechanism: regulation of aquaporin water channels by vasopressin. Am. J. Physiol. 272: 3-12.

14. Lantz, G. C., Ihle, S. L., Nelson, R. W., Carlton, W. W., Feldman, E. C., Lothrop, C. D. Jr. and Bottoms, G. D. 1988. Trans- sphenoidal hypophysectomy in the clinically normal dog. $\mathrm{Am}$. J. Vet. Res. 49: 1134-1142.

15. Lolova, I. S., Davidoff, M. S. and Yakimoff, N. A. 1996. Vasopressin- and oxytocin-immunoreactive nerve cells in the aging rat hypothalamus. Acta. Physiol. Pharmacol. Bulg. 22: 7-16.

16. Meij, B. P. 1998. Transsphenoidal hypophysectomy for the treatment of pituitary-dependent hyperadrenocorticism in dogs. Vet. Q. 20 (Suppl.) 1: S98-100.

17. Meij, B. P. 2001. History of pituitary surgery in humans and animals: from experiments with dogs to treatment of patients. Ned. Tijdschr. Geneeskd. 145: 2478-2482.

18. Meij, B. P. 2001. Hypophysectomy as a treatment for canine and feline Cushing's disease. Vet. Clin. North Am. Small Anim. Pract. 31: 1015-1041.

19. Meij, B. P., Mol, J. A., Van den Ingh, T. S., Bevers, M. M., Hazewinkel, H. A. and Rijnberk, A. 1997. Assessment of pituitary function after transsphenoidal hypophysectomy in beagle dogs. Domest. Anim. Endocrinol. 14: 81-97.

20. Meij, B. P., Voorhout, G. and Rijnberk, A. 2002. Progress in transsphenoidal hypophysectomy for treatment of pituitarydependent hyperadrenocorticism in dogs and cats. Mol. Cell. Endocrinol. 197: 89-96.

21. Meij, B. P., Voorhout, G., Van den Ingh, T. S., Hazewinkel, H. A., Teske, E. and Rijnberk, A. 1998. Results of transsphenoidal hypophysectomy in 52 dogs with pituitary-dependent hyperadrenocorticism. Vet. Surg. 27: 246-261.

22. Meij, B. P., Voorhout, G., Van den Ingh, T. S., Hazewinkel, H. A. and Van't Verlaat, J. W. 1997. Transsphenoidal hypophysectomy in beagle dogs: evaluation of a microsurgical technique. Vet. Surg. 26: 295-309.

23. Morton, A. 1970. The time course of retrograde neuron loss in the hypothalamic magnocellular nuclei of man. Brain 93: 329336.

24. Niebauer, G. W., Eigenmann, J. E. and Van Winkle, T. J. 1990. Study of long-term survival after transsphenoidal hypophysectomy in clinically normal dogs. Am. J. Vet. Res. 51: 677-681.

25. Rhodes, C. H., Morrell, J. I. and Pfaff, D. W. 1981. Immunohistochemical analysis of magnocellular elements in rat hypothalamus: distribution and numbers of cells containing neurophysin, oxytocin, and vasopressin. J. Comp. Neurol. 198: 45-64.

26. Richardson, D. W. and Robinson, A. G. 1985. Desmopressin. Ann. Intern. Med. 103: 228-239.

27. Rijnberk, A., Biewenga, W. J. and Mol, J. A. 1988. Inappropriate vasopressin secretion in two dogs. Acta. Endocrinol. (Copenh.) 117: 59-64.

28. Sasaki, S., Fushimi, K., Ishibashi, K. and Marumo, F. 1995. Water channels in the kidney collecting duct. Kidney. Int. 48: 1082-1087.

29. Villar, M. J., Meister, B., Cortes, R., Schalling, M., Morris, M. and Hokfelt, T. 1990. Neuropeptide gene expression in hypothalamic magnocellular neurons of normal and hypophysectomized rats: a combined immunohistochemical and in situ hybridization study. Neuroscience 36: 181-199.

30. Ziai, F., Walter, R. and Rosenthal, I. M. 1978. Treatment of central diabetes insipidus in adults and children with desmopressin. Arch. Intern. Med. 138: 1382-1385. 